\title{
A ESCRITURA DO LÍMITE KIERKEGAARD ANTE KANT E HEGEL ${ }^{1}$
}

\author{
Dolors Perarnau Vidal \\ Universitat Autònoma de Barcelona \\ bttp://dx.doi.org/10.15304/ag.38.1.5011
}

\section{Resumen}

El artículo tiene como objetivo hacer un recorrido por tres momentos de la escritura filosófica en los que el fenómeno del límite o frontera del pensamiento se pone claramente de manifiesto en el discurso. En primer lugar, Kant, como artífice de la productiva noción de una "frontera [Grenze]" de la razón como condición y límite del pensamiento; en segundo lugar, Hegel, como su máximo crítico en la "asunción [Aufhebung]" de la negación de la frontera kantiana; y, finalmente, Kierkegaard, cuya contribución a la discusión de sus predecesores consiste en el "pathos [Lidenskab]" del límite que Kant demarca y Hegel supera, pues en el caso del pensador danés el límite de la filosofía es al mismo tiempo paradoja, esto es, algo que no puede ser conocido sino tan sólo reconocido por la razón y que pone la razón en su límite.

Palabras clave: Kierkegaard, Kant, Hegel, razón, frontera, límite, pasión.

\begin{abstract}
The objective of the paper is to do a tour of three moments of philosophical writing in which the phenomenon of limit or boundary of thought is brought to light in the discourse. In the first place, Kant, as an author of the productive notion of "Boundary [Grenze]" of reason as a condition and limit of thought; secondly, Hegel, as his maximum critic at the "assumption [Aufhebung]" of negation of Kant's boundary; and, finally, Kierkegaard, whose contribution to the discussion of his predecessors consists in the "pathos [Lidenskab]" of the limit that Kant demarcates and Hegel surpasses, since, in the case of the Danish thinker,
\end{abstract}

Recibido: 14/03/2018. Aceptado: 29/05/2018.

${ }^{1}$ Unha primeira versión deste artigo foi presentada no marco do curso "Filosofía e Literatura" do Máster en Filosofía: Coñecemento e Cidadanía da Universidade de Santiago de Compostela. Agradezo ao profesor Óscar Parcero Oubiña a amabilidade do seu convite. 
the limit of philosophy is at the same time paradox, i. e., something that cannot be known but only recognized, something that puts reason to its limit.

Keywords: Kierkegaard, Kant, Hegel, reason, boundary, limit, passion.

De que maneira a filosofía occidental ten dado conta do seu outro? Cal é a relación que se establece con aquilo que supostamente se sitúa fóra dos límites ao tempo que se pretende comprender coa razón? Non é este xesto xa unha contradición, a contradición de determinar un outro como si mesmo na comprensión da súa determinación? Como podemos pensar o impensábel, aquilo que non é diferente ou relativo ao pensamento senón, como dirá Kierkegaard, o "absolutamente diferente para o cal non hai marca distintiva"?

Co ánimo de dar resposta a estas preguntas, o que se pretende facer nas seguintes liñas e un breve percorrido por tres momentos da escritura filosófica no que o fenómeno do límite ou fronteira do pensamento se pon claramente de manifesto. En primeiro lugar, Kant, como o filósofo pioneiro en captar aquilo que o discurso non podía entender (rol do entendemento) mais debía pensar (rol da razón). No segundo lugar, Hegel, como crítico de Kant e antecesor, á su vez, da obxección de Wittgenstein -este xa nun contexto lingüístico- ${ }^{2}$, en tanto que pensador que amosa a contradición na que Kant cae ao demarcar un límite que non pode rebasar. E, finalmente, Kierkegaard, cuxa contribución á discusión dos seus predecesores non consiste tanto en coñecer como en recoñecer o límite como paradoxo, é dicir, como algo que é en si mesmo liminar en tanto que pon en cuestión o propio pensamento; pois, como se sabe, o paradoxo di si e non á vez, e pon en entredito a lóxica de toda comprensión.

Así as cousas, Kant, como artífice da produtiva noción filosófica de límite como "fronteira [Grenze]" da razón, e Hegel, como o seu máximo crítico no ámbito da "asunción [Aufhebung]" da negación do movemento especulativo, serán vistos como os predecesores dunha problemática que

${ }^{2}$ Como é sabido, ao engadirlle o matiz dun "trazado na linguaxe”, Wittgenstein corrixe a ousadía kantiana de demarcar un límite ao pensamento. Recordemos as palabras do prólogo do Tractatus: "O libro, polo tanto, quere trazar un límite ao pensamento ou máis ben non ao pensamento senón á expresión do pensamento [dem Ausdruck der Gedanke]. Porque para trazar un límite ao pensamento teriamos que poder pensar os dous lados deste límite (é dicir, teriamos que poder pensar o que non se pode pensar). O límite, pois, só poderá ser trazado na linguaxe e o que se atopa máis aló do límite será simplemente insensatez [wird enfaich Unsinn sein]" (L. Wittgenstein, Tractatus logico-philosophicus, en Werkausgabe, 8 vols., Francfort, Suhrkamp, 1989, vol. 1., p. 9 [Tradución castelá de Jacobo Muñoz e Isidoro Reguera en Tractatus logico-philosophicus, Madrid, Alianza Editorial, 1995]). 
continúa e afonda en Kierkegaard, se ben neste último o límite xa non é un "concepto" ou "transición" senón, máis ben, o "don" e "tarefa" -como así di da propia dialéctica da existencia- ${ }^{3}$ dun pensamento que non se presenta a si mesmo como coñecedor ou sabedor de límites, senón, máis ben, como o seu sufridor. ${ }^{4}$

De aí que, malia seguir a caracterización conceptual dos seus predecesores, o límite en Kierkegaard non sexa entendido como unha realidade descoñecida ou coñecida pola filosofía (unha idealidade metafísica, sexa en negativo, en Kant, ou en positivo, en Hegel) senón como unha experiencia, é dicir, como unha realidade que ten que ser asumida e realizada pola propia filosofía e, sobre todo, pola "carne" do suxeito que a fai, o filósofo. É sen dúbida, este cambio de paradigma que vai dun interese exclusivamente epistemolóxico a un ontolóxico e, fundamentalmente, ético, o que fai de Kierkegaard un pensador que xa non fala do límite desde a abstracción e a distancia do pensamento -como se este fose un obxecto de coñecemento ou de discurso máis-, senón que o que fai -e aquí radica a súa relevancia como filósofo escritor- é dar precisamente conta do límite no propio discurso, de xeito que a este xa non lle quede máis remedio que calar. Pois a filosofía cala con Kierkegaard, tal e como acontece con Wittgenstein na proposición número 7 do seu Tractatus: "Do que non se pode falar, hai que calar"; mais no pensador dinamarqués a filosofía cala por saturación, por tela levado ao absurdo do seu propio falar. A fin de contas, o interesante en Kierkegaard non é tanto o feito de sinalar a inefabilidade da verdade cristiá no discurso filosófico -ese antigo contencioso entre fe e razón- como o de amosar desde dentro do mesmo como esta inefabilidade que é paradoxo (para-doxa: marabilla que vai en contra de toda comuna opinión) resiste a toda comprensión que non sexa aquela de comprender que non se pode comprender, e así decidirse a seguila -isto é, a imitala nun sentido cristián- desde o interese e a paixón da existencia individual.

${ }^{3} \mathrm{Na}$ súa tese doutoral, Sobre o concepto de ironia en constante referencia a Sócrates, Kierkegaard resalta o dobre aspecto da realidade existencial como simultaneamente don (Gave) e tarefa (Opgave) (cf. S. Kierkegaard, Søren Kierkegaards Skrifter, Niels Jørgen Cappelørn et. al. (eds.), 28 vols., Copenhaguen, Søren Kierkegaard Forskningscenteret, GAD, 1997-2012, vol. 1, p. 312. De agora en adiante SKS, seguido do número de volume e páxina). As traducións dos textos de Kierkegaard son sempre propias.

${ }^{4}$ Kierkegaard emprega o termo Lidenskab (padecemento ou paixón) para designar o sentir que experimenta o pensador diante do límite do seu propio coñecemento. É particularmente nas Migallas filosóficas, no capítulo que trata do paradoxo absoluto, onde o pseudónimo Johannes Climacus fala explicitamente da "paixón paradoxal do entendemento [Forstandens paradoxe Lidenskab] que choca continuamente con iso descoñecido" (SKS 4, 249). 


\section{A escritura do límite na dialéctica da fronteira kantiana}

Como é sabido, a noción de límite enraíza na filosofía crítica kantiana e na necesidade de facer fronte ao instinto aventureiro de todos aqueles que se dispoñían directamente a coñecer sen antes someter a exame crítico a capacidade do seu coñecemento. O pensamento adquire así a nobre tarefa de reflexionar sobre si mesmo e demarcar os seus propios límites.

Segundo Kant, o coñecemento está limitado ás aparencias e aos conceptos que meramente serven para entender o mundo dado pola sensibilidade. Alén diso non hai máis que un baleiro, unha realidade descoñecida, a cousa en si, na que non podemos facer pé, mais na cal tampouco podemos, con todo, deixar de pensar. Nos Prolegómenos a toda metafísica futura que poida presentarse como ciencia, Kant explica:

Por conseguinte, temos que pensar un ser inmaterial, un mundo intelixíbel e un Ser supremo (todos noumena) porque a razón só nestes, como cousas en si mesmas, encontra a perfección e a satisfacción que nunca pode esperar da derivación dos fenómenos a partir dos seus fundamentos homoxéneos, e porque os fenómenos refiren realmente a algo diferente deles (e polo tanto, completamente heteroxéneo), xa que os fenómenos presupoñen sempre unha cousa en si mesma, e por conseguinte, dan indicio dela, xa sexa que se poida coñecer máis de perto, ou que non se poida facelo. ${ }^{5}$

Se ben é certo que non podemos dar, máis aló de toda experiencia posíbel, ningún concepto determinado do que poidan ser as cousas en si, tampouco somos libres, pensa Kant, de absternos enteiramente de inquirir sobre elas, xa que a experiencia non satisfai nunca a razón. "A razón humana ten o singular destino", afirma Kant, "nun dos seus campos de coñecemento, de atoparse acosada por cuestións que non pode rexeitar por seren consideradas pola mesma natureza da razón, mais ás que tampouco pode responder por sobrepasaren todas as súas facultades". ${ }^{6}$

Así, pois, para comprender a unidade da experiencia, a razón é efectivamente capaz de pensar nunha base intelixíbel das aparencias, nun fundamento totalmente heteroxéneo que dea a satisfacción e o cumprimento que tanto necesita. Pese a non coñecer o que está pensando, a razón presupón a idea

${ }^{5}$ I. Kant, Prolegomena zu einer jeden künftigen Metaphysik die als Wissenschaft wird auftreten können (PkM), en Kants Werke, Akademie Textausgabe, Berlín, Walter der Gruyter \& CO., 9 vols., 1968, vol. IV, pp. 354-355 (Tradución castelá de Mario Caimi en I. Kant, Prolégomenos a toda metafísica futura que haya de poder presentarse como ciencia, ed. bilingüe, Madrid, Istmo, 1999).

${ }^{6}$ I. Kant, Kritik der reinen Vernunft (KrV), en Kants Werke, Akademie Textausgabe, 9 vols., Berlín, Walter de Gruyter 1968, vol. III, A VII, p. 7 (Tradución castelá de Pedro Ribas en Crítica de la razón pura, Madrid, Alfaguara, 1978). 
dunha totalidade incondicionada cara a cal remitir todas as condicións, unha realidade descoñecida que é a un tempo límite e condición do pensamento. ${ }^{7}$ E neste sentido que a razón ten un papel na formación do coñecemento, un papel non constitutivo senón regulativo, na medida que presenta un incondicionado para o coñecemento condicionado do entendemento, do cal, malia todo, non pode ter coñecemento nin presupoñer a existencia.

Mais a pregunta que temos que facer para a cuestión que nos ocupa e que considera Kant nos seus Prolegómenos ${ }^{8}$ é a seguinte: como se comporta a nosa razón respecto da relación entre aquilo que coñecemos e aquilo que non coñecemos nin coñeceremos nunca? Xa que, como afirma o autor, a ligazón do coñecido con algo completamente descoñecido é real e tense que poder, cando menos, esclarecer. ${ }^{9} \mathrm{E}$ iso é o que trata de facer Kant precisamente co concepto espacial e xeográfico de "límite ou fronteira [Grenze]", o cal distingue do concepto de "limitación ou barreira [Schranke]"; pois, segundo o alemán, mentres que as limitacións son formas privativas de negación, é dicir, só refiren ao fin dunha cousa como a liña que confina un territorio (léase terminus), as fronteiras son límites internos, é dicir, refírense ao máis acó dunha cousa é sempre en relación co máis aló (léase limes).$^{10}$ A diferenza da limitación, a fronteira presupón sempre un espazo que se atopa fóra dun certo lugar determinado e o inclúe; razón pola cal Kant afirma que o límite é "algo positivo e completo en si mesmo" por constituír o espazo da relación. ${ }^{11}$ A fronteira, xa que logo, ten a particularidade de ser un concepto de intenso carácter dialéctico, posto que é positivo e negativo ao mesmo tempo, simultaneamente apertura e clausura dos dous mundos que ela mesma pon en relación. ${ }^{12}$

${ }^{7} \mathrm{KrV}$ B 604, vol. IV, p. 388.

${ }^{8}$ Concretamente no capítulo conclusivo titulado: "Da determinación dos límites [Grenzbestimmung] da razón pura” (\$ 57-60), correspondente á terceira parte da pregunta transcendental capital: "Como é posíbel a metafísica simplemente?"

${ }^{9} \mathrm{PkM}, \mathrm{p} .354$.

${ }^{10} \mathrm{PkM}$, p. 360. Pese a importancia que ten a noción de límite na filosofía crítica kantiana, son poucos os estudos que se ocuparon da mesma (cf. A. Gentile, Ai confini della ragione. La nozione di "limite" nella filosofia transcendentale di Kant, Roma, Studium 2003, p. 194 n.1). Á parte desta obra de Gentile, cabe destacar os seguintes traballos: L. Illeterati, Figure del limite. Esperienze e forme della finitezza, Trento, Verifiche, 1996; A. Rigobello, I limiti del trascendentale in Kant, Milán, Silva, 1963; o capítulo de E. Franzini, "Limite e confini", en Filosofia del sentimenti, Milán, Mondadori, 1997, pp. 98-170; e os artigos de P. Faggioto, “'Limiti' e 'Confini' della conscenza humana secondo Kant. Commento al paragrafo 57 dei Prolegomini”, Verifiche 15 (1986), 231-242 e A. Moretto, “'Limite' e 'analogia' in alcuni aspetti della filosofia critica di Kant”, Vertifiche 15, (1986) 341-364.

${ }^{11}$ PkM, p. 352.

${ }^{12}$ Para máis detalle, véxanse as voces "Grenze" e "Schranke" en R. Eisler, Kant Lexikon, París, Gallimard, 1994. Tamén en H. Caygill, Kant’s Dictionary, Oxford, Blackwell, 1995. 
Se aplicamos a metáfora da fronteira á razón e á súa relación co descoñecido, podemos dicir que o espazo que se limita é o mundo da experiencia e o que se presenta máis aló destes límites é o mundo intelixíbel das ideas. Como Kant constata, non se pode pensar constitutivamente máis aló do mundo fenoménico, dado que iso sería usar os conceptos puros do entendemento máis aló de toda experiencia posíbel e enredarse en absurdos e contradicións (as famosas antinomías e paraloxismos da razón). E, non obstante, apunta Kant, no esforzo para comprender a unidade da experiencia, para buscar como quen di a satisfacción da razón cun incondicionado cara ao cal remitir todos os condicionados, a razón leva o entendemento máis aló de si mesmo, ata o "punto de contacto do espazo cheo (a experiencia, o mundo dos phaenomena) co espazo baleiro (do cal non podemos saber nada, o mundo dos noumena) e, ao facelo así, pon claramente a fronteira da esfera da súa aplicación. ${ }^{13}$ Desta maneira, o coñecido e o descoñecido entran en relación un co outro, encontrándose nunha ambigua situación. Vexamos como é que a describe o propio Kant:

Como procede a razón para limitar o entendemento con respecto a ambos campos? A experiencia que contén todo o que pertence ao mundo sensíbel, non se pon límites a si mesma; só pasa sempre, de cada condicionado, a outro condicionado. Aquilo que debe por límites debe xacer enteiramente fóra dela, e este é o campo dos seres intelixíbeis puros. Mais este é para nós un espazo baleiro, na medida en que se trata da determinación da natureza destes seres intelixíbeis; e en tal medida non podemos, se se pon a mira en conceptos dogmaticamente determinados, saír fóra do campo da experiencia posíbel. Mais posto que un límite [Grenze] é el mesmo algo positivo que pertence tanto ao que

${ }^{13}$ Elio Franzini afirma que o uso do vocabulario xeográfico serve a Kant para cartografar un "mapa da razón”. Desde esta perspectiva, a distinción semántica entre os límites e as limitacións devén unha distinción crucial na filosofía transcendental kantiana, xa que as limitacións poden ser traspasadas, mais os límites teñen que ser fundamentados na relación coa experiencia (op. cit, p. 99). Sendo así, Kant establece o "territorio do intelecto" e define o criterio de verdade no camiño do coñecemento: "Non soamente temos percorrido o territorio do entendemento puro e examinado coidadosamente cada parte, senón que temos comprobado, ademais, a súa extensión e sinalado a posición de cada cousa. Este territorio é unha illa que foi contida pola mesma natureza entre os límites invariábeis. É o territorio da verdade -un nome atractivo- e está rodeado por un océano amplo e borrascoso, verdadeira patria da ilusión, onde algunhas néboas e algúns xeos que se desfán prontamente producen a aparencia de novas terras e enganan unha e outra vez con vanas esperanzas o navegante ansioso de descubrimentos; levándoo a aventuras que nunca é capaz de abandonar, mais que tampouco pode concluír. Antes de aventurármonos neste mar para exploralo en detalle e nos asegurar que podemos esperar algunha cousa del, será conveniente botar unha ollada ao mapa do territorio que queremos abandonar e indagar primeiro se non poderiamos acaso contentármonos co que contén, ou ben se non teriamos que facelo por non atopar terra na cal establecérmonos” (KrV, B294-295, vol. IV, p. 202). Véxase tamén A 759/B787. 
está dentro del como ao espazo que está fóra dun conxunto dado, é un coñecemento real e positivo o que adquire a razón con só estenderse até ese límite; mais ao estenderse de tal modo que non intente sobrepasalo, porque alí encontra ante si un espazo baleiro no cal pode certamente pensar formas para as cousas, mais non as cousas mesmas. Mais que o campo da experiencia está limitado por algo que, polo demais, élle descoñecido á razón, é, non obstante, un coñecemento que aínda lle queda a razón nesta situación, coñecemento polo cal, sen quedar pechada dentro do mundo sensible, e sen extraviarse tampouco fóra del, senón do modo que corresponde a un coñecemento do límite, a razón se limita á relación de aquilo que xace fóra del límite, con aquilo que está contido dentro del. ${ }^{14}$

Limitar o coñecemento aos fenómenos implica establecer un máis aló dos propios fenómenos, unha especie de espazo aberto que está alí, mais no cal non podemos entrar. Non obstante, na fronteira de todo uso lexítimo, a razón pode pensar, cando menos, a relación: a relación entre, entre o fenómeno e o seu máis aló, entre o coñecido mundo da experiencia e o descoñecido mundo dos entes do pensamento. É claro que esta relación non é constitutiva, non designa unha relación obxectiva dun obxecto real coas cousas, senón unha relación subxectiva do noso pensamento cos seus propios obxectos. A realidade desta relación é meramente ideal (regulativa e analóxica, dirá Kant), xa que, máis que a realidade, corresponde á necesidade do noso pensamento.

Así pois, os límites do coñecemento non só nos impiden "ir máis aló" senón tamén afirmar que máis aló deles non hai nada. Ao contrario, grazas aos propios límites, a razón ve no seu entorno un espazo de realidade que non pode coñecer, mais tampouco negar. O límite ou fronteira, como aquel punto no que o espazo cheo toca co espazo baleiro, pasa a ser unha realidade de todo dialéctica en Kant: negativa e positiva á vez, restritiva e posibilitadora; límite e condición do propio pensamento.

\section{A escritura do límite na dialéctica da asunción hegeliana da negación}

Igual que Kant, Hegel diferencia o concepto de límite ou fronteira (Gren$z e$ ) do de limitación ou barreira (Schranke) mais, a diferenza do primeiro, que concibe o límite da razón como unha fronteira absoluta e infranqueábel, Hegel defíneo como unha limitación homoxénea e relativa ao propio pensamento e, polo tanto, como unha Schranke do entendemento que "debe ser" (Sollen) asumida (aufhegoben) pola propia razón. ${ }^{15}$ A contribución de

${ }^{14}$ PkM, pp. 360-361.

${ }^{15} \mathrm{Na}$ Ciencia da lóxica, Hegel relaciona a noción de Schranke (limitación) coa de Sollen (deber ser) na medida en que unha Schranke é "unha Grenze que debe ser superada”. Escribe 
Hegel é, entón, conceder unha consideración dinámica ao límite kantiano, xa que, a parte de determinar e circunscribir unha cousa, a negatividade do límite é agora aquilo que tamén inclúe dentro de si mesma o oposto da cousa, ou sexa, a propia negación.

A tese de Hegel é, de feito, simple: se podemos dicir que hai un límite, entón hai algo máis aló deste límite, e se son eu quen son consciente del, entón tamén teño que ser eu quen sexa consciente do máis aló que abre. Polo tanto, ao asignar un límite aos meus poderes cognitivos, xa estou, dalgún xeito, máis aló del. Segundo Hegel, o mesmo xesto de trazar un límite é xa signo de telo traspasado. A demarcación e a transgresión do límite han de ser dous momentos dun mesmo acto de coñecemento; e é por este motivo que na Enciclopedia das ciencias filosóficas a demarcación kantiana dos límites da razón se describe como unha empresa de todo absurda:

É por iso a maior inconsecuencia conceder, dun lado, que o entendemento só coñece fenómenos e, doutro, afirmar este coñecemento como algo absoluto cando se di que o coñecer non pode ir más aló, que ese é o límite absoluto, natural, do humano saber. As cousas naturais son limitadas e só son tales, [ou sexa,] cousas naturais, en tanto non saben nada dos seus límites xerais, namentres a súa determinidade é un límite só para nós, non para elas. Algo se sabe como límite ou falta, é máis, algo se sinte como límite ou falta só cando un, ao mesmo tempo, está más aló [diso] [...]. ${ }^{16}$

A distinción entre o que son as cousas en si mesmas e o que son para a consciencia ten que ser, por conseguinte, unha distinción trazada no seo da propia consciencia, unha distinción inherente ao propio coñecemento. Se a cousa en si fose irremediabelmente inaccesíbel e incognoscíbel, como di Kant, entón, pensa Hegel, sería simplemente inexistente. O feito de atribuírlle existencia implica coñecela, e o único que hai que facer é aumentar este coñecemento:

A limitación [Schranke], a falta de coñecemento determínanse só como limitación ou falta por comparación á idea dispoñíbel da universalidade, de algo enteiro e perfecto. É mera inconsciencia, xa que logo, non darse conta que a mesma designación

Hegel: "En canto deber ser [sollen], algo encóntrase elevado por riba da súa limitación [über seine Schranke erhaben], mais viceversa só en canto deber ser ten a súa limitación. Ambas cousas son inseparábeis. $\mathrm{O}$ algo ten unha limitación en tanto que ten unha determinación, e a determinación é tamén o ser-asumido da limitación [das Aufgehobensein der Schraknke] [, o feito de ter asumido a limitación]" (Wissenschaft der Logic en G. W. F. Hegel, Werke in zwandig Bänden, Eva Moldenhauer e Michel Karl Markus (eds.), Francfort, Suhrkamp, 20 vols., 1969-1971, vol. 5, p. 143 [Tradución castelá de Félix Duque en Ciencia de la lógica. Volumen 1: La lógica objetiva, Madrid, Abada Editores / UA Ediciones, 2011).

${ }^{16}$ G. W. F Hegel, Enzyclopädie der Philosophischen Wissenschaften en Werke in zwandig Bänden, op. cit., vol. 8, \$60, p. 144 (Tradución castelá de Ramón Valls Plana en Enciclopedia de las ciencias filosóficas en compendio, Madrid, Alianza Editorial, 1999). 
de algo como finito ou limitado inclúe a proba da presenza efectiva do infinito [der wirklichen Gegenwart des Unendlichen] e o ilimitado, que o saber sobre o límite [Grenze] só pode darse cando o que está falto de límite está situado deste lado, na consciencia. ${ }^{17}$

Con esta obxección, Hegel asume e dinamiza a un tempo a sutil e capital distinción que Kant establecía na Crítica da razón pura, a saber, a diferenza real, profunda e insuperábel entre a orde do pensar e a orde do coñecer, entre a facultade do "entendemento [Verstand]" e a da "razón [Vernunft]". Lembremos que para Kant hai cousas que poden e deben ser pensadas, mais non hai maneira humana de coñecelas. Un hiato separa as ideas da razón das realidades ignotas ás cales fan referencia, e é xustamente esta separación o que fai que a empresa de demarcar os límites da razón sexa factíbel e necesaria. É máis, a diferenza que hai entre o que pode ser coñecido e o que só pode ser pensado esixe e permite a Kant o acto de demarcar un límite ao coñecemento; un límite que, como fronteira, confina o noso coñecemento ao tempo que o abre a un máis aló incognoscíbel. Mais Hegel non pode aceptar esta distinción como un límite estático e fixado a priori; xa que, para el, a área do que pode ser pensado é, de maneira inmediata, a área do coñecer ou, mellor dito, a área do "coñecemento absoluto [absolute Wissen]". Aínda que mantén a distinción kantiana entre Verstand e Vernunft, Hegel interpreta a súa relación de xeito distinto. Pois segundo o pensador suabo, a actividade e a forza do entendemento, como a facultade dos conceptos e do xuízo, é a de separar os opostos, cousa que a vincula á fixeza e repouso; mentres que a razón, como facultade das ideas, ten a capacidade dialéctica e especulativa de ex-por as contradicións que hai implícitas nas abstraccións do entendemento e reconcilialas, cousa que a vincula á fluidez, ao movemento e ao devir. ${ }^{18}$ Por este motivo, se Hegel converte a Grenze nunha mera Schranke é en virtude de recuperar a Vernunft coma facultade cognoscitiva, en tanto que a razón non está nel restrinxida polo insuperábel límite da experiencia posíbel, senón constituída pola negatividade das súas determinacións.

En vez da fronteira kantiana que nos alerta do descoñecido e da "ilusión [Shein]" que causa o seu pretendido coñecemento, o límite é en Hegel a barreira que hai que sobrepasar para adquirir un coñecemento, non transcen-

${ }^{17}$ Idem. Véxase tamén Wissenschaft der Logic, op. cit., vol. 5, pp. 119-122.

${ }^{18}$ Véxase Phänomenologie des Geistes en Werke in zwanzig Bänden, op. cit., vol. 3, pp. 35-38 (Tradución castelá de Antonio Gómez Ramos en G. W. F. Hegel, Fenomenología del espíritu, Madrid, UAM /Abada, 2010). 
dental nin ideal, senón "real [wirklich]" do descoñecido $;^{19}$ un coñecemento superior e máis elevado en tanto que integrador do momento necesario no que o saber incorpora a súa propia negatividade. Desta maneira, paraloxismos e antinomías non son máis consecuencia do avance dunha razón impotente, que cae en contradición e se confunde ela mesma; senón, ao contrario, marca negativa do avance dunha razón que se supera. ${ }^{20}$

Lonxe de ser limitada como en Kant, a razón hegeliana preséntase capaz de resolver as contradicións nunha unidade superior, de reconducir as diferenzas cara a identidade. Velaí a esencia da dialéctica hegeliana e velaí o límite kantiano convertido no "momento de negación [Moment der Negation]" da súa lóxica: "o que é lóxico, segundo a forma, ten tres momentos: a) o abstracto ou propio do entendemento; b) o dialéctico ou racionalnegativo; g) o especulativo ou racional-positivo". ${ }^{21}$ Inserido no movemento desta lóxica, o límite devén o "motor" do proceso dialéctico: "o negativo [das Negative], ${ }^{22}$ dado que é xustamente "aquilo co que a razón se enfronta", unha "determinada negación [bestimmte Negation]" ${ }^{33}$ que, unha vez asumida (aufgehoben), proporciona un coñecemento máis elevado, o coñecemento absoluto.

Polo tanto, e volvendo ao asunto do noso interese, se ben Hegel non elimina o carácter fronteirizo do límite -xa que, máis ben, lle da unha entidade ao consideralo un punto polo cal a razón debe pasar-, si é certo que o insire no propio movemento do Espírito e, ao facer tal cousa, convirte a absoluta negatividade da fronteira nunha transición, é dicir, nunha Grenze que se dá e se experimenta en tanto que Schranke e, por conseguinte, "coa finalidade de ser superada". ${ }^{24}$

Hegel leva así a metáfora kantiana até as últimas consecuencias, porque cando dicimos con el que entre o entendemento e a razón hai unha fronteira, queremos dicir que estas non son facultades enteiramente heteroxéneas,

19 A distinción entre Realität (realidade dada) e Wirklichkeit (realidade que se dá de maneira efectiva) é fundamental para entender a filosofía hegeliana, posto que é no segundo dos termos que Hegel entende superar a Kant. Segundo aquel, no mundo danse realidades que son como deben ser, realidades que se adecúan ao propio concepto ou esencia e que son, xa que logo, realidades efectivas, "realidades en si" tamén para nós.

${ }^{20}$ Véxase a crítica que fai Hegel ás antinomías kantianas na Enzyklopädie, op. cit., $\mathbb{} 48$, 126ss.

${ }^{21}$ Enzyklopädie, op. cit., $\mathbb{\$} 79$, p. 168.

${ }_{22}$ Phänomenologie, op. cit., p. 39.

${ }^{23}$ Ibidem, p. 73.

${ }^{24}$ Wissenschaft der Logic, op. cit., pp. 142-148. 
senón pertencentes a un mesmo territorio. Hegel non vén dicir que a razón teña límites, senón que é límite, nacemento da tensión dun mesmo proceso de negación e determinación. Como consecuencia, tanto o límite como o seu máis aló acaban formando parte dun mesmo camiño, do inmanente camiño de progreso e necesidade da lóxica dialéctica dunha razón especulativa.

\section{A escritura do límite na dialéctica da paixón kierkegaardiana}

Sexa pola renuncia de coñecer o descoñecido, sexa pola pretensión de coñecelo na súa totalidade, ambos os dous, Kant e Hegel, semellan concluír dunha vez por todas a cuestión filosófica do límite. Por unha banda, Kierkegaard é do parecer xuntamente con Hegel que, pese ao seu pietismo, Kant peca da hybris de demarcar os seus propios límites; a fin de contas, a razón é en Kant o "tribunal supremo" e a que decide en todo momento o que pode ou non pode coñecerse. ${ }^{25}$ Mais Kierkegaard tamén acusará Hegel de pretender ofrecer un dominio ilimitado do límite, de non preservar o misterio e segredo que hai nel. Segundo o dinamarqués, Hegel pecha definitivamente todo interrogante respecto do límite e o seu máis aló, ao eliminar de raíz ambas cousas coa total e sistemática comprensión da realidade. ${ }^{26}$

\section{A negatividade do límite}

Distanciándose dun e doutro, máis desde a súa evidente influencia, Kierkegaard prefire adoptar o ethos grego de manterse constantemente no "esforzo [Stræben]" cara ao límite, tal como facían por outra banda os escépticos que tanto admiraba, a existencia dos cales radicaba xustamente na

${ }^{25} \mathrm{KrV}, \mathrm{B} 697$, vol. III, p. 442.

${ }^{26}$ Se ben a totalidade hegeliana pode ser entendida de xeito metafísico (un todo como condición e fundamento das partes) ou postmetafísico (un todo accesíbel só nas súas partes, posterior), en ambos os dous casos trátase dunha totalidade que, como tal, ten a característica de non permitir que exista nada externo a ela, de non haber nada que non estea incluído ou se lle escape. En consecuencia, toda alteridade ou diferencia queda subsumida e perde, por conseguinte, o carácter de xenuíno outro. En Temor e tremor, Johannes de silentio exprésao nos seguintes termos: "A filosofía hegeliana non acepta o dereito a ningún ocultamento, a ningunha inconmensurabilidade" (SKS 4, 172). Como apunta Félix Duque, na súa edición da Ciencia da lóxica, en Hegel quedaría eliminada toda posíbel transcendencia absoluta, expresión que nin tan só ten sentido no Sistema, xa que se se transcende é sempre "de algo ou alguén e, polo tanto o transcendente xa está nalgunha relación co transcendido, de maneira que non pode ser absoluto" (op. cit., p. 74). 
"escepsis", é dicir, en manter o problema "sempre in suspenso". ${ }^{27}$ Como explica Climacus, o pseudónimo máis filosófico de todos os de Kierkegaard:

[O escepticismo grego] en todo momento utilizaba o coñecemento só para conservar a disposición [Sindelag], que era a cuestión principal; e por iso nin sequera estaba disposto a declarar $\theta \varepsilon \tau \imath \kappa \omega \varsigma$ ["positivamente"] o resultado negativo do coñecemento, por verse atrapado na formulación dunha conclusión..$^{28}$

Como sabemos, a cuestión para Kant era toda outra: fundamentar "una metafísica como ciencia" ${ }^{29}$ e, por iso, acabou usando o coñecemento, ou mellor dito, o límite do coñecemento, en beneficio desta. E o mesmo fixo Hegel co tamén positivo resultado da negación da negación, ao usar a negatividade en pro dunha posterior mediación. Kierkegaard, pola contra, emula o talante daquel pensador subxectivo existente do que fala Climacus na Apostila que, sendo consciente da negatividade do infinito na súa propia existencia, "conserva permanentemente aberta a ferida da negatividade [holder bestandigt dette Negativitetens Saar aabent] (SKS 7, 84) e non se deixa enganar polo positivo. Escribe Climacus:

O pensador subxectivo existente que ten a infinitude na súa alma, tena sempre, de aí que a súa forma sexa continuamente negativa. Se isto é así, se el, que existe realmente, reproduce a forma da súa existencia no seu existir, entón, en canto existente, é incesantemente tanto negativo como positivo, xa que a súa positividade consiste naquela incesante interiorización en virtude da cal é consciente do negativo [den fortsatte Inderliggiørelse, i hvilken han er vidende om det Negative]. Entre os denominados negativos, pola contra, hai algúns que despois de teren chegado a saber algo sobre o negativo engánanse co positivo e van polo mundo a berros, recomendando, impoñendo, ofertando á venda a súa beatífica sabedoría negativa. ${ }^{30}$

Neste senso, Kierkegaard é da opinión que a debilidade do sistema kantiano radica na cousa en si, ${ }^{31}$ mais -nótese- non porque se delimite o seu coñecemento -como criticaran despois os idealistas posteriores, entre eles, Hegel- senón porque non se reduplica á súa negatividade, porque Kant, como pensador, non é aínda suficientemente subxectivo como para pensar e existir á vez no límite que demarca. Así o confirma Climacus no seguinte fragmento:

A diferenza entre o pensamento subxectivo e o pensamento obxectivo tamén ten que atopar expresión na forma da comunicación, é dicir, o pensador subxectivo ten que

\footnotetext{
${ }^{27}$ SKS 4, 281.

${ }^{28}$ SKS 4, 282.

${ }^{29} \mathrm{KrV}$, B XVI, vol. III, p. 11-12.

${ }^{30}$ SKS 7, 84.

${ }^{31}$ SKS 1, 309.
} 
darse logo conta de que a forma ha de estar dotada artisticamente de tanta reflexión como a que el mesmo ten na medida en que existe no seu pensamento. ${ }^{32}$

O pensador subxectivo "non é un home de ciencia, senón un artista. Existir é unha arte" -asegura Climacus na Apostila. ${ }^{33}$ Porque, a diferenza de Kant, Kierkegaard preocúpase de comunicar o límite baixo a forma esencialmente adecuada, cousa que significa comunicalo de acordo coa existencia e non desde o falso dominio dun punto de vista eterno e metafísico. ${ }^{34}$ Kant, en cambio, é indiferente á realidade existencial do cognoscente; a fin de contas, el si que é e quere ser un home de ciencia, un home do saber universal, e por este motivo pon o límite ao servizo da idea, ao servizo da exposición científica obxectiva. ${ }^{35}$

Con todo, do que é ou deixa de ser o límite, Kant non fala en absoluto. ${ }^{36} \mathrm{O}$ ignotum kantiano resulta así unha resposta demasiado pouco ética para un pensador cuxa tarefa é xustamente "estar esencialmente interesado no seu propio pensamento e existir nel". ${ }^{37}$ Mais tamén o é a resposta de Hegel, que fala do límite de xeito especulativo. Kierkegaard rexeitará todo discurso sobre o límite, mais tamén rexeitará a ulterior posibilidade de renunciar filosoficamente á cuestión. É certo que o que hai máis aló da fronteira sobrepasa as nosas capacidades, mais o enigmático carácter do que nos transcende non pode constituír unha barreira ou prohibición para a razón filosófica, xa que é precisamente o seu estímulo, malia ser á vez o "tormento [Qval]" da súa paixón. ${ }^{38}$ Tal como apunta Climacus emulando a crítica hegeliana ao límite kantiano:

A intelixencia non vai máis aló, mais tampouco pode no seu paradoxo deixar de chegar até alí e ocuparse diso, xa que querer expresar a súa relación con iso descoñecido, dicindo que non existe, non encaixa, posto que esta declaración agocha xustamente unha relación. ${ }^{39}$

Así pois, Kierkegaard non renunciará á filosofía, mais fará que esta estea repetidamente renunciando a si mesma; dun lado, ao obrigala a pensar o

32 SKS 7, 74.

${ }^{33}$ SKS 7, 321.

${ }^{34}$ Cf. SKS 7, 80-92.

${ }^{35} \mathrm{Na}$ segunda edición da Crítica da razón pura, Kant fai explícita a vontade de emular na súa obra "o camiño seguro da ciencia" (KrV B XV-XVI; B XVIII, vol. III, p. 11-12; p. 13).

${ }^{36} \mathrm{O}$ mesmo acontece con Wittgenstein e o "sen sentido" do Tractatus; e por iso "hai que calar".

${ }^{37}$ SKS 7, 73.

${ }^{38}$ SKS 4, 249.

${ }^{39} \mathrm{Idem}$. 
descoñecido, doutro, ao obrigala a expresalo. Con todo, non se pensará nin se dirá nada; mais, con esta repetida negatividade do discurso, o límite poderá continuar sendo aquilo que é: unha "absoluta infinita negatividade", en termos da ironía socrática kierkegaardiana, ${ }^{40}$ que, en virtude de ser consciente de si mesma, ten malia todo o carácter positivo de abrirnos cara a aquilo que clausura.

\section{O ser do limite}

Kierkegaard segue Kant no feito de trazar un límite ao coñecemento. Das Ding an sich é algo que a razón non pode concibir, un "concepto límite" máis aló do cal non é posíbel ir. ${ }^{41}$ Agora ben, o an sich kantiano é demasiado abstracto e indeterminado polo interese kierkegaardiano. $\mathrm{O}$ an sich non pode ser un vedado diante do cal volver as costas e retroceder sen máis ou simplemente calar -como fará o Wittgenstein do Tractatus- porque en Kierkegaard o límite xa non é só aquilo que hai no noso pensamento, senón aquilo que é e no que consiste a propia existencia: "a principal dor da existencia”, escribe Kierkegaard nos seus cadernos, "é que desde o comezo estou en contradición comigo mesmo, que o verdadeiro ser da persoa vén mediante unha oposición". ${ }^{2}$

Indo un paso máis aló do criticismo kantiano, Kierkegaard non di que a razón ou o ser humano teña límites, senón que é fundamentalmente límite, fronteira ou liña de contacto entre dous mundos que fai próximas as terras e, non obstante, distantes. É agora o existente quen se atopa na encrucillada das dualidades insuperábeis que Kant subliñaba na súa filosofía (fenómeno/ cousa en si, ser/deber, natureza/liberdade) e Hegel pretendía unificar en virtude da mediación. A negación e a diferenza insírense así na propia "carne" do pensador e o límite xa no é só a condición (Kant) ou transición (Hegel) do pensamento, senón o don e a tarefa de todo aquel que está obrigado a existir, "a contradición [Modsigelsen]" contra a cal loita repetidamente o individuo a fin de devir si mesmo. Escribe Climacus:

A realidade [Virkelighed] dunha persoa real [virkelig], composta de infinitude e finitude, radica precisamente no feito de soster xuntas estas dúas, manténdose infinitamente interesada en existir". ${ }^{43}$

${ }^{40}$ SKS $1,82$.

41 "O concepto de noúmeno non é máis que un concepto límite [Grenzbegriff] destinado a pór vedado ás pretensións da sensibilidade” (KrV A 255, vol. IV, p. 166).

${ }^{42}$ Pap. IV B 10a (S. Kierkegaard, Søren Kierkegaards Papirer, P. A. Heiberg, V. Kuhr e E. Torsting (eds.), 16 vols., Copenhaguen, Gyldendal, 1968-1978).

${ }^{43}$ Cf. SKS 7, 275. En Kierkegaard a contradición significa sempre unha tarefa. Véxase, por exemplo, SKS 4, 354; SKS 7, 321; 345-347 et passim. 
A existencia humana preséntase así baixo a forma dunha paradoxal dialéctica, posto que os extremos da fronteira son irreconciliábeis e o existente está condenado a ser para sempre o seu punto converxente, o limes que a un tempo conxunta e disxunta a heteroxeneidade das terras. Como diría o pseudónimo Vigilius Haufniensis: a "síntese de alma [Sjel] e corpo [Lege$m e] " 44$ e como Anti-Climacus engadiría: a "síntese de infinitude [Uendelighed] e de finitude [Endelighed], do temporal [Timelige] e do eterno [Evige], de liberdade [Fribed] e de necesidade [Nødvendighed]". ${ }^{45}$

Chegar a ser si mesmo significa pois nada máis e nada menos que facerse límite, devir ou chegar a ser a relación de síntese que un xa é; de tal maneira, que calquera identificación da relación cun dos extremos da síntese terá como contrapartida a perda do si mesmo. E cómpre dicir que esta é unha perda moito máis radical que a que presentaba Kant coa ilusión das antinomías, porque a perda, ou mellor dito, a traizón ao ser fronteirizo que somos é o que Anti-Climacus denomina biblicamente "enfermidade para a morte [Sygdommen til Døden]"; unha enfermidade que cala en todo individuo cando, non asumindo o límite que é, desespera por esquecer ou perverter o delimitador aspecto do finito ou o extensivo aspecto do infinito que lle son igualmente constitutivos. ${ }^{46}$

$\mathrm{O}$ individuo en tanto que síntese existe en simultánea finitude e infinitude e estas, á súa vez, non son entendidas como espazos que están máis acó ou máis aló da fronteira existencial que é; senón que se sitúan no propio atopos do límite, isto é, na dialéctica dunha finitude que xa non é deficitaria e falta de infinitude, senón infinitamente apaixonada, esforzada e interesada no propio existir. ${ }^{47} \mathrm{E}$ é aquí onde atopamos a contribución kierkegaardiana ao respecto da escritura filosófica do límite, a saber, na relación patética que un tal ser establece coa "unidade negativa [negative Eenhed]" que aínda non é e, non obstante, xa é. Só un concepto como o de "pathos [Lidenskab]" podía dar conta da calidade desta peculiar relación, pois a paixón non só indica a tensión da fronteira, senón que a vive no dobre movemento do que ela tamén goza: ao arelar unha cousa e, polo tanto, apaixonarse, e ao padecer pola súa causa. Devir límite significa, pois, padecer (at lide) a contradición que un é na propia carne, soster e resistir a vertixe que provoca o

${ }^{44}$ SKS 4, 349.

${ }^{45}$ SKS 11, 129.

${ }^{46} \mathrm{Na}$ Enfermidade para a morte, o pseudónimo Anti-Climacus realiza un diagnóstico da enfermidade do "desespero [Fortvivlelse]" nos termos aludidos.

${ }^{47}$ SKS 7, 38. 
abismo do seu ser e tomar unha actitude ao respecto con interese e apaixonamento. ${ }^{48}$

\section{O discurso do limite}

Unha das consecuencias que implica o feito de que o límite se faga ontolóxico, a propia "carne" do pensador, é que aquel xa non se poida describir ou trazar desde a neutralidade dun suxeito que coñece, posto que agora o límite é aquilo que xustamente describe e traza o propio coñecemento. Este é o xiro copernicano que realiza Kierkegaard ao respecto do límite dos seus predecesores, porque, a diferenza do criticismo kantiano que o demarca ou do movemento especulativo que o trata de superar, Kierkegaard bate continuamente contra o límite e fai deste bater o motivo do discurso. Dito doutra maneira, o pensador dinamarqués xa non discursa de ou sobre o límite, xa que en todo caso fai do límite o pathos do discurso, a tensión e a contradición que padece a propia linguaxe ao bater repetidamente contra algo que non pode expresar e do que, pese a todo, ten que dar conta. ${ }^{49}$

${ }^{48}$ Escribe Climacus nas Migallas filosóficas: "Todo devir [tilblivelse] é un padecemento [Liden] e o necesario non pode padecer, non pode sufrir o padecemento da realidade" (SKS 4, 274). Así mesmo, nunha discusión sobre o padecemento do relixioso e do cómico na Apostilla, este mesmo pseudónimo afirma que "o padecemento é precisamente a consciencia da contradición" (SKS 7, 438).

${ }^{49}$ Cómpre sinalar aquí a relevancia dun concepto como o de "repetición [Gjentagelse]" en oposición ao de mediación. Constantin Constantius, o pseudónimo que se interroga polo seu concepto, escribe: "A repetición é a nova categoría a descubrir [...] no fondo, a repetición é aquilo que, erroneamente, denominouse 'mediación'. É incríbel canta gala fixo da mediación á filosofía hegeliana, e canto estúpido aplauso se cubriu de gloria e honor baixo este emblema [...] No noso tempo non se explica nin como aparece a mediación, nin se resulta do movemento dos momentos dobres, nin de que maneira o que é previamente xa está incluído naqueles ou ben se é algo novo que intervén, e se é así, de que forma” (SKS 4, 25). Para o contexto da mediación e repetición como dialécticas enfrontadas, véxase André Clair, "Médiation et Répétition. Le lieu de la dialectiques kierkegaardienne", Revue des sciences philosophiques et theologiques 59 (1975), 38-78. Tamén é de sumo interese o estudo monográfico de Niels Nymann Eriksen, quen subliña a importancia da categoría de repetición no desenvolvemento do pensamento filosófico do século XX, aludindo exemplos como a noción de historicidade heideggeriana de Ser e Tempo e a Diferenza e repetición de Gilles Deleuze. É nesta última onde se afirma que Kierkegaard e Nietzsche "fit de la répétition non seulment une puissance propre du langage et de la pensé, un pathos et une pathologie supérieure, mais la catégorie fondamentale de la philosophie de l'avenir" (Différence et Répétition, París, Universitaires de France, 1968, p. 12). Para máis detalle, véxase o estudo de Niels Nymann Eriksen, Kierkegaard's Category of Repetition, Kierkegaard Studies Monograph Series, vol. 5, Berlín, Walter de Gruyter, 2000, pp. 1-2. 
Así como pasa co pensamento, o límite deixa entón de ser un "obxecto de discurso" máis para pasar a ser aquilo contra o que o discurso trope$\mathrm{za}$, aquilo co que se encontra a linguaxe no propio curso do seu discorrer (dis-curso), no seo da lóxica do seu encadeamento racional. Como choque e confrontación, polo tanto, o discurso sofre unha interrupción, unha suspensión e unha ferida do sentido que toma a forma dun silencio na propia palabra.

O discurso kierkegaardiano convértese, así, nun discurso patolóxico, o discurso do "padecemento [Lidenskab]" do logos, no que o logos non se limita nin se supera a si mesmo, senón que, máis ben, padece e pasa pola paixón de confrontarse con algo que vén de fóra e co que, non obstante, ten que tratar. Escribe Climacus:

A paixón paradoxal do entendemento [Forstandens paradoxe Lidenskab] bate continuamente con iso descoñecido, que existe, mais que é tamén descoñecido e, neste sentido, non existe [...] Mais que é este descoñecido [dette Ubekjendte]? Porque que sexa o deus [Guden], non significa simplemente para nós que é o descoñecido? Afirmar del que é o descoñecido, porque non se coñece e, mesmo, no caso de coñecelo non podería expresarse, non satisfai a paixón, aínda que esta conciba correctamente o descoñecido "como límite [som Graendse]". O límite é precisamente "o tormento da paixón [ $L i$ denskabens Qval]", malia ser ao tempo o estímulo. En todo caso non pode ir máis aló tanto se se atreve cunha saída via negationis como via eminentiae..$^{50}$

Como vimos, nin o esforzo por coñecer o descoñecido nin o esforzo por renunciar a el poden darse na súa completude, poden satisfacer desta vez a paixón no seu paradoxo. A tendencia inherente da razón por coñecer o que non pode ser coñecido exprésase aquí en todo o seu patetismo. É por iso que, cando o entendemento bate frontalmente contra o seu propio "límite [Grcendse]", non queda parado, mais tampouco colle o impulso para se superar, senón que se apaixona e padece (lider) profundamente o choque. O entendemento queda así "afectado [lidende]", arela alcanzar o límite que o constrinxe, mais padece, ao mesmo tempo, a impotencia de alcanzalo. $\mathrm{O}$ descoñecido preséntase negativamente na forma dun afecto; solicita o pensamento, mesmo cando o limita; o límite "tormenta" e "incita" e non hai maneira de evadirse.

Máis que pretender descubrir ou superar o propio límite, o entendemento topa no seu curso cun paradoxo que non pode concibir e que lle afecta de maneira absoluta. O límite xa non se relaciona coa existencia como algo accidental e transitorio, senón, antes ao contrario, como algo constitutivo

${ }^{50}$ SKS 4, 249. 
que revoluciona completamente a existencia do pensador e a interpela á espera dunha resposta. O paradoxo kierkegaardiano non é nada posto, xa que, de feito, é o mesmo paradoxo quen pon o entendemento na súa paixón paradoxal, se ben este non o pense e crea telo posto el mesmo. Porén, malia o paradoxo non ser obxecto da realización do pensador, este vese na obriga de pronunciarse.

A situación do límite kierkegaardiano preséntase así nun contexto de "liberdade trabada [hildet Frihed]", como dirá o pseudónimo Vigilius Haufniensis en $\mathrm{O}$ concepto de angustia, na mesma condición de receptividadeactividade dun termo como o de "paixón [Lidenskab]". ${ }^{51}$

Situado no medio desta ambigua e patética situación, o pensador será compelido a escollerse en relación cun "Ou...ou [Enten-Eller]" ben decisivo: ou se escandaliza e, tomando o paradoxo como indicador do cumio do movemento racional, teima en entender o que non se pode entender, ou se escandaliza e, tomando o paradoxo como escándalo real, sosteno con todas as súas forzas, salta por encima do escándalo e abraza a fe a fin de relacionarse con aquilo que, non sendo "diferente" da razón, é, máis ben, "o absolutamente diferente para o cal non hai marca distintiva"; cousa que significa que é diferente de maneira impensábel e inefábel. Continua Climacus:

Se o descoñecido (o deus) non permanece unicamente límite [blot bliver Groendse], entón un único pensamento fúndese en moitos pensamentos tocante ao diferente. $\mathrm{O}$ descoñecido é entón na $\delta \imath \alpha \sigma \pi o \rho \alpha$ e o entendemento ten a grata elección entre o que el pode e o que a imaxinación e capaz de inventar (o monstruoso, o ridículo, etc. etc.). ${ }^{52}$

Pensar o límite como algo outro que o propio límite, como idea transcendental (Kant) ou especulativa (Hegel), por exemplo, é facer da diferenza un obxecto de pensamento e, polo tanto, perder o límite como algo absoluto ao pensamento, perdelo absolutamente. Por iso, á inversa do que pasa coas filosofías do seus predecesores, as cales exercen un dominio ilimitado do límite, Kierkegaard fere a filosofía desde dentro e fai simplemente patente o límite no discurso da mesma. Velaí a reduplicación kierkegaardiana da negatividade da fronteira kantiana: a razón non só comprende o límite "como límite [som Groendse]", ${ }^{33}$ senón que existe e se comprende a si mes-

${ }^{51}$ Do latín passio o do grego $\pi \dot{\alpha} \theta 0 \varsigma$, a paixón ten o carácter bifronte de significar tanto o feito pasivo de padecer unha afección pola acción dun outro, como o feito activo, connatural ao propio termo, de reaccionar ao respecto de maneira intensa e emotiva.

${ }_{52}$ SKS 4, 250.

${ }^{53}$ Véxase tamén SKS 1, 218, 243. 
ma nese límite, implicando con iso toda unha serie de estratexias e recursos literarios que, xunto coa pseudonimia, farán que a filosofía queira o seu propio silencio. ${ }^{54}$

Así, pois, na medida en que leva o discurso da filosofía até o límite, Kierkegaard quebranta a filosofía e a fai tremer coa resonancia daquilo que nunca poderá concibir. Neste senso, Johannes Climacus e Johannes de silentio comparten moito máis que o seu propio nome, xa que cada un á súa maneira confrontará a filosofía co seu límite e fará que o padeza no seu propio discurso: o primeiro, confrontándoa coa hipótese dunha verdade revelada, a cristiá, pois é nas Migallas filosóficas que Climacus deixa a filosofía feita anacos ao obrigala a pensar nunha verdade eterna cun punto de partida histórico; e o segundo, coa fe, pois é en Temor e tremor onde de silentio fai sentir a fe de Abraham de maneira que á filosofía non lle queda máis remedio que calar. Enten-eller: ou Sócrates ou Cristo -di Climacus-, Enten-eller: ou Hegel ou Abraham -di de silentio-; mais, en calquera caso, ningún dos dous se pronuncia a favor dun lado ou outro da alternativa, senón que simplemente se sitúan, tamén eles, na fronteira que escenifican ao remarcar a diferenza por mor da diferenza mesma.

Xa que logo, e por primeira vez na tradición filosófica -a cal, como di Jacques Derrida, sempre tivo o celo de dicir o seu propio límite, apropiándose e até dispoñendo del-, ${ }^{55}$ a negatividade do límite non se di nin se comprende, senón que simplemente se experimenta; faise experiencia do límite no discurso da propia filosofía.

Dalgún modo, pois, e xuntamente con Nietzsche, Kierkegaard pon os fundamentos dunha nova maneira de filosofar na que o límite da filosofía, negado e asumido pola propia filosofía, é recuperado e feito presente no propio texto filosófico, precisamente como aquilo que resiste ao pensamento, como aquilo que é repetidamente irredutíbel.

\footnotetext{
${ }^{54}$ Isto é, segundo Olivia Blanchette, o que sucede nunha obra como Temor e tremor dun Johannes apelidado, non por casualidade, “de silentio". Véxase ao respecto: "The Silencing of Philosophy", en International Kierkegaard Commentary: Fear and Trembling, and Repetition, Robert L. Perkins (ed.), Macon: Mercer University Press, 1993, pp. 29-65.

55 "[la philosophie] a toujours tenu à s'assurer la maîtrise de la limite (peras, limes, Grenze). Il l'a reconnue, conçue, posée, déclinée selon tous les modes possibles; et dès lors du même coup, pour mieux en disposer, transgressée. Il fallait que sa propre limite ne lui restât pas étrangère. Il s'en est donc appropié le concept, il a cru dominer la marge de son volume et penser son autre" (J. Derrida, Marges de la philosophie, París, Les Éditions de Minuit, 1972 p. I).
} 


\section{Conclusión}

Lonxe de condicionar o coñecemento (Kant) ou ser o momento necesario para o progreso da razón (Hegel), o límite en Kierkegaard inscríbese na mesma tensión da existencia, como algo que vén dado mais que é tamén tarefa do individuo realizar. A negatividade do límite kierkegaardiano non só limita a razón senón que, como vimos, a afecta, e a afecta de tal maneira que chega a turbala, mesmo a perturbala no seu curso, no seu discurso. Paradoxo, absurdo e escándalo son así, non tan só "conceptos" no pensamento de Kierkegaard, senón conceptos "negativos" e "fronteirizos" -como el mesmo os designa- ${ }^{56}$ que trazan o padecemento da razón no propio discurso; marcas ou trazos negativos da descontinuidade dun discurso que, pese a non poder dicir o límite, vese na obriga de amosalo desde o "dis" (no sentido do prefixo latín "contra a" máis tamén do grego "mal", "difícil") da continuidade do seu curso, na descontinuidade do discurso.

É por este motivo que nin Kierkegaard nin os seus pseudónimos son quen de demarcar ou simplemente superar o límite coa razón; senón que o que fan é poñer máis ben de manifesto o límite como tal, na paixón e o padecemento dunha razón que "bate contra el" e se dá conta que fracasa, que non pode concibir o que, non sendo condición (Kant) nin impulso (Hegel) é o repetido "tormento" da súa "paradoxal paixón". ${ }^{57}$

Por vez de entender a negatividade do límite como medio para a autofundamentación ou autosuperación do pensamento, Kierkegaard considera a negatividade do límite como a cruz da razón, o particular viacrucis polo que ten que pasar a razón de querer chegar a un entendemento co seu propio límite, de querer establecer algún tipo de relación con aquilo que é "absolutamente diferente [....]" que ela mesma, e que, lonxe de ser unha restrición meramente negativa do pensamento (Schranke), é a real fronteira da existencia humana; o "interese [inter-esse] da metafísica" e simultaneamente "aquel interese no cal encalla [strander] a metafísica" -por dicilo co pseudónimo Constantius Constantius. ${ }^{58}$

56 “ $\mathrm{O}$ absurdo, o paradoxo son compostos de tal maneira que a razón non ten en absoluto o poder de disolvelos nunha insensatez [Nonsens]. En xeral, é un erro básico pensar que non hai conceptos negativos [negative Begreber]; os máis altos principios de todo pensamento ou das súas probas son certamente negativos. A razón humana ten límites [Groendser], e é alí onde se atopan os conceptos negativos. As loitas de fronteira [Groendsefcegtningen] son negativas, obrigan a repregarse" (SKS 23, 24 [NB15:25]).

${ }^{57}$ SKS 4, 249.

${ }^{58}$ SKS 4, 25-26. 
Porque sen ben é certo que en tanto que cruz e paixón o límite continua sendo en Kierkegaard un cruzar e pasar, tal como era, por outra banda, en Hegel, a diferenza radica no "como [hvorledes]" deste pasar, no feito de que o pasar sexa agora no padecemento e en virtude dunha "transición [Overgang]" que é, á parte de dialéctica, patética. Por dicilo coas palabras do propio Kierkegaard no quinto dos discursos cristiáns do "Evanxeo dos sufrimentos [Lidelsernes Evangelium]": a diferenza radica en "como un camiña polo camiño da vida [hvorledes man gaaer paa Livets Vei]", ${ }^{59}$ que traducido aos termos agora mencionados equivalería a dicir: en como un camiña polo camiño da negatividade. Pois se a negatividade do límite kantiano ou, mesmo, o camiño da negatividade do espírito hegeliano non son aínda suficientes para achegarse ao límite do discurso é porque, segundo Kierkegaard, non é o camiño que é negativo senón a negatividade o camiño. O que marca a diferenza e diferencia o camiño kierkegaardiano é, xa que logo, o feito que sexa un camiño a través da cruz e a paixón, non da comprensión, do descoñecido.

Poderiamos dicir, sen ánimo de esgotala, que o conxunto da obra kierkegaardiana é, dalgún xeito, a historia desta paixón, a historia de como o logos foi atravesado polo pathos, de como a Palabra existe como padecemento e é vivida como morte na cruz. O camiño da cruz, non o regulativo ou o especulativo da razón é, así, o único camiño que leva ao límite, xustamente porque non hai outros, porque os outros, como din as escrituras, son “camiños errados [Afveie]", ${ }^{60}$ camiños que levan á perdición.

En suma, contrariamente a Kant, Kierkegaard asume con Hegel a función positiva do límite en tanto que punto de pasaxe transitábel, mais faino cun como diferente: non como lugar de superación (Aufhebung), senón como lugar de paso e impasse ao mesmo tempo e, xa que logo, como lugar de cambio e transformación existenciais. ${ }^{61}$ Deste xeito, e por dicilo con Blanchot, o paso do límite convértese nun Pas au-delà, nun paso (non) máis aló do límite, por ser "paso [Gang]" que se "nega a si mesmo [fornegter sig $s e l v] " 62$ e que é, máis ben, froito dunha "caída [Undergang]" ${ }^{63}$ Pese a todo,

${ }^{59}$ SKS 8, 385.

${ }^{60}$ SKS 8, 393.

${ }^{61}$ SKS 7, 521.

${ }^{62}$ SKS 8, 323.

${ }^{63}$ En relación coa categoría do "salto [Spring]", escribe Kierkegaard: "a doutrina do movemento (a transición [Overgangen]) (Non no lugar, non fóra do lugar). Velaí o salto. O camiño humano [den msklige Gang] é, xa que logo, unha caída [en Falden]" (SKS 27, 276 [Papir283:1]). Véxase tamén SKS 4, 243. 
é este paso, o que, ao transitalo repetidamente coa paixón -e non dunha vez por todas coa razón- sitúa o individuo no lugar adecuado, no bo camiño; no propio límite, nin aquén nin alén.

\section{Bibliografía}

Blanchette, O., “The Silencing of Philosophy”, en International Kierkegaard Commentary: Fear and Trembling, and Repetition, Robert L. Perkins (ed.), Macon, Mercer University Press, 1993, pp. 29-65.

Caygill, H., Kant's Dictionary, Oxford, Blackwell, 1995. https://doi.org/10.1111/b.9780631175353.1995.x

Clair, A., "Médiation et Répétition. Le lieu de la dialectiques kierkegaardienne", Revue des sciences philosophiques et theologiques 59 (1975), 38-78.

Deleuze, G., Différence et Répétition, Paris, Universitaires de France, 1968.

Derrida, J., Marges de la philosophie, Paris, Les Éditions de Minuit, 1972.

Duque, F., Ciencia da Lógica, Volumen 1: La lógica objetiva, Madrid, Abada Editores / UA Ediciones, 2011.

Eisler, R. , "Grenze”, Kant Lexikon, Paris, Gallimard, 1994.

Faggioto, P., "'Limiti' e 'Confini' della conscenza humana secondo Kant. Commento al paragrafo 57 dei Prolegomini”, Verifiche 15 (1986), 231242.

Franzini, E., Filosofia del sentimenti, Milano, Mondadori, 1997, pp. 98170.

Gentile, A., Ai confini della ragione. La nozione di "limite" nella filosofia transcendentale di Kant, Roma, Studium 2003.

Kant, I., Kants Werke, Akademie Textausgabe, Berlin, Walter de Gruyter \& CO., 9 vols., 1968.

Kant, I., Crítica de la razón pura, Madrid, Alfaguara, 1978.

Kant, I., Prolégomenos a toda metafísica futura que haya de poder presentarse como ciencia, ed. bilingüe, Madrid, Istmo, 1999.

Kierkegaard, S., Søren Kierkegaards Papirer, P. A. Heiberg, V. Kuhr e E. Torsting (eds.), 16 vols., København, Gyldendal, 1968-1978.

Kierkegaard, S., Søren Kierkegaard Skrifter (SKS), Niels Jørgen Cappelørn, Joakim Garff, Johnny Kondrup, Alastair Mckinnon e Finn Hauberg Mortensen (eds.), 28 vols., København, Søren Kierkegaard Forskningcenteret, GAD, 1997-2012.

${ }^{64}$ SKS 1, 354. 
Hegel, G. W. F., Werke in zwanzig Bänden, Eva Moldenhauer e Karl Markus Michel (eds.), Frankfurt/Main, Suhrkamp, 20 vols., 1969-1971.

Hegel, G. W. F., Enciclopedia de las ciencias filosóficas en compendio, Madrid, Alianza Editorial, 1999.

Hegel, G. W. F., Fenomenología del espíritu, Madrid, UAM /Abada, 2010.

Hegel, G. W. F., Ciencia de la lógica. Volumen 1: La lógica objetiva, Madrid, Abada Editores / UA Ediciones, 2011.

Illeterati, L., Figure del limite. Esperienze e forme della finitezza, Trento, Verifiche, 1996.

Moretto, A., "'Limite' e 'analogia' in alcuni aspetti della filosofia critica di Kant”, Vertifiche 15 (1986), 341-364.

Nymann Eriksen, N., Kierkegaard's Category of Repetition, Kierkegaard Studies Monograph Series, vol. 5, Berlin, Walter de Gruyter, 2000. https://doi.org/10.1515/9783110825824

Rigobello, A., I limiti del trascendentale in Kant, Milano, Silva, 1963.

Wittgenstein, L., Werkausgabe, 8 vols., Frankfurt/Main, Suhrkamp, 1989.

Wittgenstein, L., Tractatus logico-philosophicus, Madrid, Alianza Editorial, 1995. 